\title{
Introduction to the Special Issue: Resilience and Wellbeing in Forced Migration
}

\author{
Denise Lewis ${ }^{1}$ and Alexander Rödlach ${ }^{2}$
}

\begin{abstract}
This set of articles is the result of a panel held at the 78th annual meeting of the Society for Applied Anthropology from April 3-7, 2018, in Philadelphia, United States of America. The title of the panel, during which the four authors presented papers, was "Forced Migration as Liminal Experience: Policy and Agency." The articles highlight forced migration to the United States, illustrated by Hispanic women without legal immigration status near Chicago, Illinois; resettled Syrian refugees in Austin, Texas; resettled Cambodian refugees living near Mobile, Alabama; Karen refugees resettled near Atlanta, Georgia; and Karenni refugees who were resettled in Omaha, Nebraska. These articles reveal lives of both refugees with legal status and forced migrants without legal documentation. This set of articles also represents national and ethnic groups from Latin America, the Middle East, and Southeast Asia, regions with large numbers of forced migrants. The articles focus on the intersection of three concepts with complex and varying definitions: migration, resilience, and wellbeing. These concepts highlight differing social and cultural contexts but also shared experiences and struggles. We briefly describe our understanding of these concepts and then highlight how these are useful conceptual frameworks to see commonalities and differences among the four different case studies.
\end{abstract}

Keywords: forced migration; refugees; resilience; wellbeing.

\section{Introduction}

This set of articles ${ }^{3}$ is the result of a panel held at the $78^{\text {th }}$ annual meeting of the Society for Applied Anthropology from April 3-7, 2018, in Philadelphia, United States of America. The title of the panel, during which the four authors presented papers, was "Forced Migration as Liminal Experience: Policy and Agency."

The articles highlight forced migration to the United States, illustrated by Hispanic women without legal immigration status near Chicago, Illinois; resettled Syrian refugees in Austin, Texas; resettled Cambodian refugees living near Mobile, Alabama; Karen ${ }^{4}$ refugees resettled near Atlanta, Georgia; and Karenni ${ }^{5}$ refugees who were resettled in Omaha, Nebraska. These articles reveal lives of both refugees with legal status and forced migrants without legal documentation. This set of

\footnotetext{
${ }^{1}$ Denise C. Lewis, Department of Human Development and Family Science, University of Georgia, 201 Family Science Center II (House D), 405 Sanford Dr., Athens, GA 30602, United States. E-mail: denise.lewis@uga.edu.

${ }^{2}$ Alexander Rödlach, Department of Cultural and Social Studies, Creighton University, Creighton Hall 441A, 2500 California Plaza, Omaha, NE 68178, United States. E-mail: roedlach@creighton.edu.

${ }^{3}$ We acknowledge and are grateful for Stephanie Armes, a doctoral candidate from the University of Georgia, who meticulously improved the formatting of this set of articles.

${ }^{4}$ The Karen refugees highlighted in the article by Lewis and Young refer to their home nation as Burma, rather than Myanmar.

${ }^{5}$ Like the Karen, also the Karenni, who are the focus of Rödlach's article, tend to refer to their country of origin as Burma.
} 


\section{Introduction to the Special Issue}

articles also represents national and ethnic groups from Latin America, the Middle East, and Southeast Asia, regions with large numbers of forced migrants.

The articles focus on the intersection of three concepts with complex and varying definitions: migration, resilience, and wellbeing. These concepts highlight differing social and cultural contexts but also shared experiences and struggles. We briefly describe our understanding of these concepts and then highlight how these are useful conceptual frameworks to see commonalities and differences among the four different case studies.

Due to the wide range of forced migration experiences of the five groups presented in the articles, we use a very general definition of migration that will be helpful for framing these articles. Conventionally, a forced migrant is considered to be someone who, because of fear of persecution, has abandoned her or his residence in favor of relocating elsewhere, either within or beyond the borders of her or his country of residence (UNHCR, 2018). More specifically, we consider forced migration to be a permanent or semi-permanent movement of persons over a significant distance, having both a chronological and a spatial aspect. Oftentimes, this movement involves the crossing of a geopolitical boundary by one or more persons involved in a change of residence (Kok, 1999, 20; Shaw, 1975). While the conventional understanding of a forced migrant emphasizes the fear of persecution as the central motivation to migrate, we acknowledge that social inequalities threaten the lives of individuals and certain demographic groups, forcing decisions to either remain and endure various forms of suffering or take what they consider to be a less risky option and migrate. While refugees have obtained legal status, undocumented migrants are not legally recognized and protected by the international community. However, refugees and undocumented immigrants share many of the same concerns. In fact, commonalities among refugees and other forced migrants are often more pronounced than are differences.

Survival migration, a more inclusive definition of forced migration, seems more appropriate in discussions of the groups represented in these four articles. Survival migration highlights the conditions under which a person cannot gain access to a fundamental set of basic human rights in his country of origin and must seek those rights in another country. Survival migrants can be defined as "persons who are outside their country of origin because of an existential threat for which they have no access to a domestic remedy or resolution" (Betts, 2013, 23). All demographic groups in the four articles can be called survival migrants. Survival migration can be a form of resilience; however, if the move worsens migrants' lives, migration cannot be considered successful (Adger et al., 2011).

The articles highlight areas of resilience in the groups described. Resilience has various, sometimes conflicting meanings, but is generally defined as the ability of an individual or community to absorb external stress (Adger et al., 2002) and "bounce back" after experiencing stress (Wald et al. 2006). Stress refers to external factors, such as changes in government policy, civil strife, difficulties to find education and employment, struggles to make ends meet, and difficulties to live according to cultural expectations (Adger et al., 2002). Moreover, resilience is the ability of a group to use its assets to strengthen their physical, behavioral, and social health which allows them to withstand, adapt to, and recover from adversity and successfully interact with others in the host nation (United States Department of Health and Human Services, 2015). However, the dynamic interplay of the social, cultural, economic, and political environments of receiving nations can create a breakdown in communication - making the health and wellbeing of forced migrants a constantly moving target (Choi, 2013; Kandula, Kersey \& Lurie, 2004).

Stress negatively affects wellbeing. Resiliency allows a counteraction of that negative effect. Individual and community characteristics, social networks, and available resources can all be 
applied to create resiliency (Meadows et al., 2015). Related to such an understanding of resilience are terms such as hardiness, referring to a personality type that can handle stress and strain effectively (Bartone et al., 1989); sense of coherence, denoting how individuals perceive and respond to events in their lives (Antonovsky, 1993); as well as flourishing or post-traumatic growth, highlighting functioning at higher levels and experiencing a greater sense of wellbeing than before the stress occurred (Carver, 1998; Tedeschi \& Calhoun, 2004). Survival migrants' resilience ultimately influences their overall sense of wellbeing. There is no common conceptualization of wellbeing but most definitions focus on an individual's or community's sense of life satisfaction (Veenhoven, 1991). Wellbeing is a multidimensional phenomenon that relates to several dimensions of people's lives identified by individuals and their communities as essential for them to flourish and fulfill their potential. These dimensions include physical health, psychosocial conditions, social relations, and economic circumstances (Stiglitz et al., 2009; Wiseman \& Brasher, 2008).

All of the papers address issues related to resilience and wellbeing. Kohl analyzes the experiences of Hispanic women in the United States. They are without legal status in the United States of America and are under the constant threat of being deported. The fear of deportation and the difficulty to have recourse in the legal system makes them particularly vulnerable. However, the United States of America, recognizing the vulnerability of these Latinas and the need to offer protection, provides a path to legal status and ultimately citizenship in cases of domestic and other forms of abuse. The Latinas, who experienced domestic abuse, must document their abuse and can draw on the support of non-governmental organizations providing legal assistance. The women are often motivated by their concern and love for their children to initiate the application process for legal status. Ironically, the concern for their children frequently traps them in abusive relationships because they do not want to leave the children behind. However, when their children are threatened, they often get the courage to contact support services to help them change their legal status. These Latinas can, after gaining legal status, rebuild their lives without the fear of deportation. They can start a life as American citizens drawing on the support of their social network and services available to them.

The Syrian refugees described by Mzayek have gained recognition and legal status as refugees, opening up the possibility of resettling in a host country. However, receiving recognition as refugees does not necessarily translate to access to needed services. Syrian refugees report that they generally have to wait for long periods of time before resettling in the camps. Mzayek describes these long periods as liminal waiting times that are filled with uncertainty. Syrian refugees have developed a unique set of resilience tactics and strategies to survive and maintain a healthy sense of self and community. After resettling in the United States of America, they met new and different challenges and struggled particularly with being separated from their social networks. They faced a need for cultural and social adaptations. Creating a tight-knit community helped them not only maintain their sense of self and community but also strengthened their resilience when facing various kinds of challenges in adapting to living in the United States of America. Their challenges ranged from individual concerns to broader political changes.

Such challenges are also evident in the voices of resettled Cambodian and Karen refugees analyzed by Lewis and Young. They echo the Syrian refugees' references to the importance of strong ethnic bonds and communities for rebuilding their lives. Lewis and Young show that lives and needs of resettled refugee families are often shaped by traumatic experiences before and during flight, yet this, along with their will and rights to make decisions regarding their lives, is often ignored. To ensure successful integration of resettled refugees, and improve our understanding of 


\section{Introduction to the Special Issue}

resettlement, Lewis and Young argue there is a need to focus strongly on the journey from home countries to resettlement, particularly how refugees frame and respond to stressors associated with those journeys. Lewis and Young assert that refugees' voices bring to light the resiliency of these groups. They describe families' collective resilience to address their wellbeing. Because it is vitally important to recognize the power of refugees' stories and explanations of events, Lewis and Young include refugees' personal narratives describing their journeys, which include fleeing their homelands, living in refugee camps, resettling in the Southeastern United States of America, and rebuilding their lives as refugees in foreign lands.

The Karenni in Rödlach's article originate from the same nation as the Karen described in the article by Lewis and Young. The Karenni illustrate how challenges become somewhat more manageable and resilience can increase through shared social and cultural networks with other forced migrants and residents at their resettlement site. Rödlach describes how Karenni membership in the Roman Catholic Church, shared beliefs encouraging the provision of support for the marginalized, as well as organizational structures shared with local Catholics and their leadership enable them to access support that might otherwise not be available to them. These factors resulted in improvements in health and wellbeing.

Together, the four articles present the complexity of forced migrants' resilience and how this resilience influences their wellbeing. All migrants described and analyzed exhibit resilience at different migration stages, however, while they are able to maintain a sense of self and collective identity, some are more successful than others. Every voice is unique; every exertion of power and agency tells the story of resilience and determination. Those who provide services to forced migrants, such as social workers, case workers, healthcare providers, friends, and other community members, become part of forced migrants' lives. While these new relationships can be nourishing, they can also be stressful, be taxing, and usurp the power of migrants who struggle with myriad transitions in relationships. Relying on others for help as they pursue safety, seek and create a sense of community, and engage in collective responsibility can increase resiliency and wellbeing. Much depends on circumstances, such as legal realities and resources available to them. In other words, an individual's resilience is strongly dependent on what the international community, national governments, non-government organizations, and communities provide. The current global political climate with nationalistic, populist, and occasionally xenophobic tendencies is likely to further reduce the already minimal support for forced migrants, furthering their existential limbo and reducing their ability to rebuild their lives.

\section{References}

Adger, W. N., Kelly, P. M., Winkels, A., L. Q. Huy, and Locke C. (2002). Migration, remittances, livelihood trajectories, and social sesilience. Ambio, 31, 4: 358-366.

https://doi.org/10.1579/0044-7447-31.4.358

Adger, W. N., Barnett, J., Chapin, F. S., and Ellemore, H. (2011). This must be the place: Underrepresentation of identity and meaning in climate change decision-making. Global Environmental Politics, 11, 2: 1-25.

https://doi.org/10.1162/GLEP_a_00051

Antonovsky, A. (1993). The structure and properties of the sense of coherence scale. Social Science and Medicine, 36, 6: 725-733.

https://doi.org/10.1016/0277-9536(93)90033-Z 
Bartone, P. T., Ursano, R. J., Wright, K. M., and Ingraham, L. H. (1989). The impact of a military air disaster on the health of assistance workers: A prospective study. Journal of Nervous and Mental Disease, 177: $317-$ 328.

https://doi.org/10.1097/00005053-198906000-00001

Betts, A. (2013). Survival migration: Failed governance and the crisis of displacement. Ithaca: Cornell University Press.

https://doi.org/10.7591/cornell/9780801451065.001.0001

Carver, C. S. (1998). Resilience and thriving: Issues, models, and linkages. Journal of Social Issues, 54: 245266.

https://doi.org/10.1111/0022-4537.641998064

Choi, J. Y. (2013). Reconstruction of health-seeking behaviors: A comparative study of three Asian Pacific immigrant groups. Qualitative Health Research, 23(4), 517-530.

https://doi.org/10.1177/1049732312469731

Kandula, N. R., Kersey, M., \& Lurie, N. (2004). Assuring the health of immigrants: What the leading health indicators tell us. Annual Review Of Public Health, 25, 357-376.

https://doi.org/10.1146/annurev.publhealth.25.101802.123107

Kok, P. (1999). The Definition of migration and its application: Making sense of recent South African census and survey Data. South African Journal of Demography, 7, 1: 19-30.

Meadows, S. O., Miller, L. L., and Robson, S. (2015). Airman and Family Resilience. Santa Monica: Rand Corporation.

Shaw, R. P. (1975). Migration Theory and Fact. Philadelphia: Regional Science Research Institute.

Stiglitz, J. E., Sen, A. and Fitoussi, J. P. (2009). Report by the Commission on the Measurement of Economic Performance and Social Progress. Retrieved from http://stiglitz-sen-fitoussi.fr

Tedeschi, R., and Calhoun, L. (2004). Posttraumatic growth: Conceptual foundations and empirical evidence. Psychological Inquiry, 15: 1-18.

https://doi.org/10.1207/s15327965pli1501_01

UNHCR (2018). The 1951 Refugee Convention. Retrieved from http://www.unhcr.org/en-us/1951-refugeeconvention.html

United States Department of Health and Human Services. (2015). Community resilience. Retrieved from http://www.phe.gov/Preparedness/planning/abc/Pages/community-resilience.aspx.

Veenhoven, R. (1991). The four qualities of life: Ordering concepts and measures of good life. Journal of Happiness Studies, 1: 1-39.

Wald, J., Taylor, S., Asmundson, G. J. G., Jang, K., and Stapleton, J. (2006). Literature Review of Concepts - Psychological Resiliency. Toronto: Defense R\&D Canada.

Wiseman, J. \& Brasher, K. (2008). Community wellbeing in an unwell world: Trends, challenges, and possibilities. Journal of Public Health Policy, 29, 3: 353-366.

https://doi.org/10.1057/jphp.2008.16 


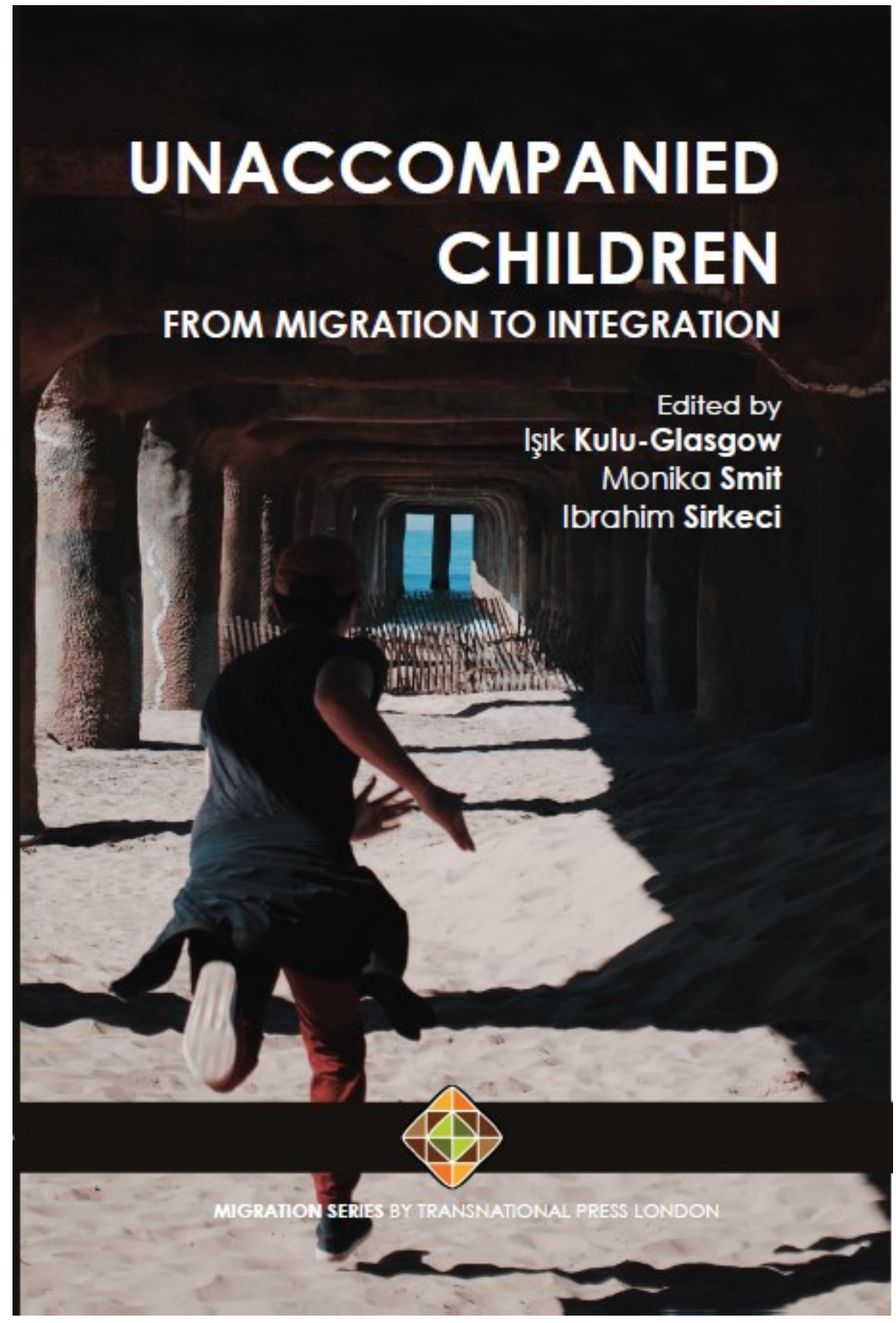

Visit Transnational Press London

www.tplondon.com 